Revista Monografias Ambientais - REMOA v. 14, 2015, p.18-24

EDIÇÃO ESPECIAL: PÓS GRADUAÇÃO EM EDUCAÇÃO,

INTERDISCIPLINARIDADE E TRANSVERSALIDADE

- UNIPAMPA - SÃO GABRIEL - RS

\title{
Análise e sensibilização dos alunos de uma escola pública nas ações sobre educação ambiental
}

\author{
Analysis and awareness among students of a public school about Environmental Education actions \\ Maria Aparecida Possati dos Santos ${ }^{1}$, André Carlos Cruz Copetti² \\ 1Pós-graduanda em Educação, Universidade Federal do Pampa, UNIPAMPA, São Gabriel, RS, Brasil. \\ ${ }^{2}$ Orientador, Professor, Doutor, Universidade Federal do Pampa, UNIPAMPA, São Gabriel, RS, Brasil.
}

\begin{abstract}
Resumo
O artigo apresenta os aspectos percebidos durante a ação ocorrida em uma escola de Ensino Médio Estadual sobre as questões relacionadas com a educação ambiental e a problemática do lixo. O grupo de pesquisa escolhido foi o Curso Normal, visto que o mesmo tem como base a formação de professores, e estes, são muitas vezes os multiplicadores de boas práticas de ações no que se refere ao tema escolhido. A formação de professores, sensibilizados para a Educação Ambiental, busca atender as necessidades atuais da sociedade, onde um educador além de suas atividades pedagógicas, torna-se um exemplo a ser seguido, dentro da comunidade em que o mesmo está inserido, é um dos instrumentos fundamentais para a realização de ações ambientais na escola onde os profissionais egressos do curso Normal irão atuar. Por isso as atividades de exploração foram previamente desenvolvidas como questionários e Rodas de Conversa.
\end{abstract}

Palavras-chave: Educação Ambiental, escola, lixo, cidadania.

\begin{abstract}
This paper presents the perceived aspects during an action occurred in a State High School about questions related to environmental education and the problem of waste. The research group chosen was Curso Normal, because it's based on teachers training, and they are often multipliers of good practices of actions referred to the chosen theme. The teachers training, aware of environmental education, tries to fulfill the current needs of society, where an educator besides the teaching activities, becomes an example to be followed, in the community where he/she is located, it's one of the essential instruments to take environmental actions at the school where the Curso Normal professionals will work. Therefore, the exploration activities were previously developed as questionnaires and conversation circles.
\end{abstract}

Keywords: Environmental Education, school, waste, citizenship. 
Santos , et al.: Análise e sensibilização dos alunos de uma escola pública...

\section{Introdução}

A educação é um processo contínuo, faz parte das atividades humanas, ocorre de maneira formal (na escola) e não formal (na vida cotidiana), onde se constituem em trocas de conhecimentos, vivências, experiências, hábitos e valores, que são conservados e passados de ao longo do tempo em geração a geração. A educação ambiental, por sua vez, torna-se uma forma abrangente da educação, onde se propõe atingir os cidadãos, em seus diferentes níveis de conhecimento, através de um processo pedagógico participativo e permanente que procura difundir no educando uma consciência crítica sobre a problemática ambiental, compreendendo-se na capacidade de captar a origem e a evolução de problemas ambientais da atualidade (GODINHO, 2013).

A educação ambiental deve ser transformadora, capaz de ser produtora de mudanças de atitudes e pensamentos, operando no campo da sensibilização e conscientização da pessoa no sentido de desenvolver senso de responsabilidade com relação aos problemas ambientais. A Educação ambiental, acontece em duas dimensões: EA formal, que é um processo que ocorre dentro do sistema escolar utilizando-se da interdisciplinaridade para implantar os princípios da relação entre: ser humano e ambiente, no conteúdo programático, devendo ser contextualizado juntamente com a realidade local; e a EA Informal, que se caracteriza por sua prática fora do contexto escolar, na vida social, onde precisa ser levada em conta o ambiente da comunidade para a qual será preparado, levantando o seu perfil, os aspectos sociais, as suas carências: econômicos e culturais, delineando as possibilidades, os métodos e as técnicas que melhor se aplica ao perfil traçado (DIAS, 2004).

Segundo Muniz (2007), a Educação Ambiental deve considerar o Meio Ambiente como um todo, deve ser sucessiva, abranger todas as faixas etárias, ocorrer dentro e fora do contexto da Escola e principalmente, analisar as questões ambientais locais, nacionais e internacionais, sob uma abordagem interdisciplinar.

A indústria com o passar dos anos, produz uma grande quantidade de embalagens descartáveis, agravando consideravelmente os problemas ambientais motivados por uma sociedade consumista. Isso faz com que os recursos naturais se tornassem insuficientes e a natureza degradada, sem condições de reagir sozinha, dando início ao colapso ambiental contemporâneo, como por exemplo, as enchentes, os desabamentos de encostas, o desmatamento desenfreado, entre outros. Os eventos climáticos extremos são classificados como grandes desvios de um estado climático moderado que têm potencial de destruição: furacões, chuvas intensas, vendavais e as grandes secas. (MARENGO 2009).

Em Kyoto, no Japão, foi assinado pelos países industrializados, um protocolo com metas quantitativas de redução de GEE ( Gases do Efeito Estufa). Estes compromissos foram estabelecidos de modo diferenciado e estão compreendidos em um intervalo de variação entre uma redução de $8 \%$ e um aumento de 10\% das emissões, sendo que essas metas "devem" ser atingidas entre 2008 e 2012 (PEREIRA; MAY; 2003). No entanto estamos em 2015 e vemos que pouco se fez para que estas reduções ocorressem.

O aumento da população acarreta em uma ampla produção de bens para consumo, aliada ao marketing incentivo à compra e por consequência criando uma maior geração de resíduos com destinação inadequada (DIAS, 2004). Em breve, haverá tanto lixo que a população estará convivendo diariamente com os resíduos muito próximos às suas residências, atraindo moscas, baratas e ratos, além de adquirir doenças oriundas destes vetores (PEDRINI,1997).

A destinação do lixo produzido é um fator preocupante, pois os aterros sanitários estão sendo criados lentamente (por força de multas). O descaso com os problemas ambientais ocorrem devido a falta de interesse por parte dos governantes, de haver mais investimentos no setor ambiental, difundindo as ações de Educação Ambiental nas escolas e nas comunidades. A população por sua vez, possui dificuldades em mudar seus hábitos, criando novos conceitos de sustentabilidade. 
Neste ponto de vista, torna-se imprescindível identificar os hábitos e atitudes dos alunos durante o seu dia-a-dia escolar, procurado intervenções que permitam que isto seja permanente no cotidiano escolar, formando cidadãos conscientes e atuantes nas práticas relacionadas com a sustentabilidade. No entanto, os profissionais que atuam diretamente com os alunos devem obrigatoriamente ter a habilidade de trabalhar os Temas Transversais nas escolas, principalmente os relacionados ao meio ambiente.

\section{Objetivo}

O objetivo do presente trabalho é relatar e discutir as ações relativas à educação ambiental direcionada para o curso Normal, tendo em vista a necessidade de formar cidadãos conscientes quanto à preservação do meio ambiente, da qualidade de vida das pessoas, da preservação dos recursos naturais, promovendo desta forma os princípios da educação ambiental junto a estes alunos, para que possam, através de dinâmicas e oficinas, criar uma consciência ecológica para promover a sustentabilidade do meio em que vivemos.

\section{Metodologia}

O presente estudo foi realizado no Instituto Estadual de Educação Menna Barreto, no Município de São Gabriel, RS. ,A escolha pela escola foi motivada devido ser a única escola estadual do município com formação de professores.

Os estudos teóricos realizados sobre o tema da Educação Ambiental, durante o curso de Especialização e Educação: Interdisciplinaridade e Transversalidade, formam muito importantes para oportunizar momentos de reflexão sobre o dia-a-dia da docência. A partir disso foi realizada esse trabalho tendo como base uma abordagem metodológica qualitativa procurando identificar e analisar as vivências dos alunos durante o curso de formação, no que se refere a temática "Educação Ambiental" e, em consequência, como podem ser abordados os temas, na sala de aula, através de oficinas. Os alunos que fazem parte deste estudo são: 25 alunos do $1^{\circ}$ ano, 13 alunos do $2^{\circ}$ ano e 11 alunos do $3^{\circ}$ ano, no período da tarde, único turno do curso.

Para tal, no mês de junho foi feita um encontro com a coordenadora do curso, onde foi apresentada a proposta da ação. Através da coordenação do curso, foi escolhido a segunda quinzena de julho para realizar a intervenção, momento em que iniciou-se as discussões sobre as ações que contribuem para que o educando saia da zona de conforto, revendo seus próprios conceitos.

Os alunos separados por turma, responderam um questionário com questões abertas e fechadas, sobre o tema proposto, cada turma ganhou um código de identificação. Após recolher o questionário 1, foram abertas as discussões e a criação da palavra-chave do painel e posteriormente os alunos responderam o questionário 2, sendo este com as mesmas perguntas. Os dados formam separados por turmas, e inseridos em planilha Excel, para a organização e análise. As questões buscaram verificar o entendimento sobre Educação Ambiental, perguntando conceito, sobre a possibilidade de trabalhar o tema nas salas de aula e a contribuição da Educação Ambiental na sociedade.

A Roda de Conversa foi elaborada em forma de semicírculo, onde os alunos abordaram os assuntos: Educação Ambiental, lixo, reciclagem e cidadania. Posteriormente os alunos montaram um painel com palavras-chave relacionadas com o tema abordado. Cada aluno explicava o porquê da palavra escolhida e o significado para a mesma. O diálogo agregou conhecimentos sobre o tema, onde abriu-se uma oportunidade para aqueles alunos tímidos, ou que possuem dificuldades de expressarse.

\section{Resultados e discussão}


No início da atividade, os alunos entenderam o objetivo proposto, bem como as opiniões foram as mais diversas possíveis. Enquanto alguns estavam interessados em mostrar suas dúvidas e opinar sobre os temas abordados, alguns alunos não demonstraram tanto interesse. Ficou bem claro que a escola possui um papel fundamental, estimulando os alunos sobre as questões ambientais desde cedo, na educação básica. A criança participando de algumas ações torna-se um cidadão responsável ambientalmente. O cuidado com o lixo não é algo "feio", ou "careta", e sim algo prazeroso, que a pessoa sabe que está fazendo a sua parte para minimizar os impactos ambientais, e muitas vezes torna-se uma fonte de renda para as famílias.

A discussão foi proveitosa e atingiu os objetivos propostos, pois grande parte dos alunos expôs sua opinião durante a Roda de Conversa. Não houve dificuldade em propor a atividade e os alunos sentiram-se à vontade para dialogar e expor suas ideias. Os problemas abordados foram de interesse dos grupos visto que se tratava de situações da vida cotidiana de cada um.

Uma das perguntas respondidas foi em relação ao conceito de Educação Ambiental, e as respostas formaram dois grupos, um deles abordou como um processo de ensino para a sociedade onde as pessoas aprenderiam a cuidar do meio ambiente com forte foco na questão de reciclagem do lixo e outro grupo como uma qualidade das pessoas, como uma característica intrínseca ao cidadão. Das 49 respostas 31 delas apontaram como processo de ensino e 18 como uma qualidade pessoal antes da Roda de Conversa. Porém após, a resposta não foi muito diferente, embora tenha diminuído para 27 respostas como processo de ensino e 22 como qualidade pessoal ou algo sobre natureza, generalizando o tema.

Essas respostas mostram que muitos estudantes ainda não enxergam o termo Educação Ambiental como um processo de transformação contínua e de hábitos que levam à sustentabilidade. Após a roda de conversa, as respostas não mudaram, inclusive reduziu o número de respostas relacionando como processo de ensino/formação.

Para Jacobi, (2003) a produção de conhecimento deve basicamente contemplar as inter-relações do meio social com o natural, juntamente com a análise dos determinantes do processo, o papel dos múltiplos atores envolvidos e as formas de organização social tendem a aumentar o poder das ações alternativas de um novo desenvolvimento, em uma perspectiva que priorize o novo perfil de desenvolvimento, com destaque na sustentabilidade socioambiental. Leff (2001) descreve a impossibilidade de resolver os complexos problemas ambientais e reverter suas causas sem que ocorra uma modificação radical nos sistemas dos valores, de conhecimento e dos comportamentos causados pela dinâmica de racionalidade existente, fundada no aspecto econômico do desenvolvimento.

Quando perguntou-se sobre a contribuição da Educação Ambiental, houve forte tendência de relacionar como o tema lixo e poluição, embora apenas 6 respostas mencionaram a palavra lixo. No entanto, não houve respostas abordando sub-temas como água, energia, diversidade e gestão de recursos. Após a intervenção, a qual houve troca de conhecimento entre os participantes, aumentou o número de vezes em que a palavra lixo foi mencionada.

Também foi relatado que durante a vida estudantil apenas um encontro tipo oficina ou palestra ocorreu abordando o tema meio ambiente.

Nas Figuras 1,2 e 3 estão os painéis com as palavras-chaves relacionadas com o tema Educação Ambiental. 


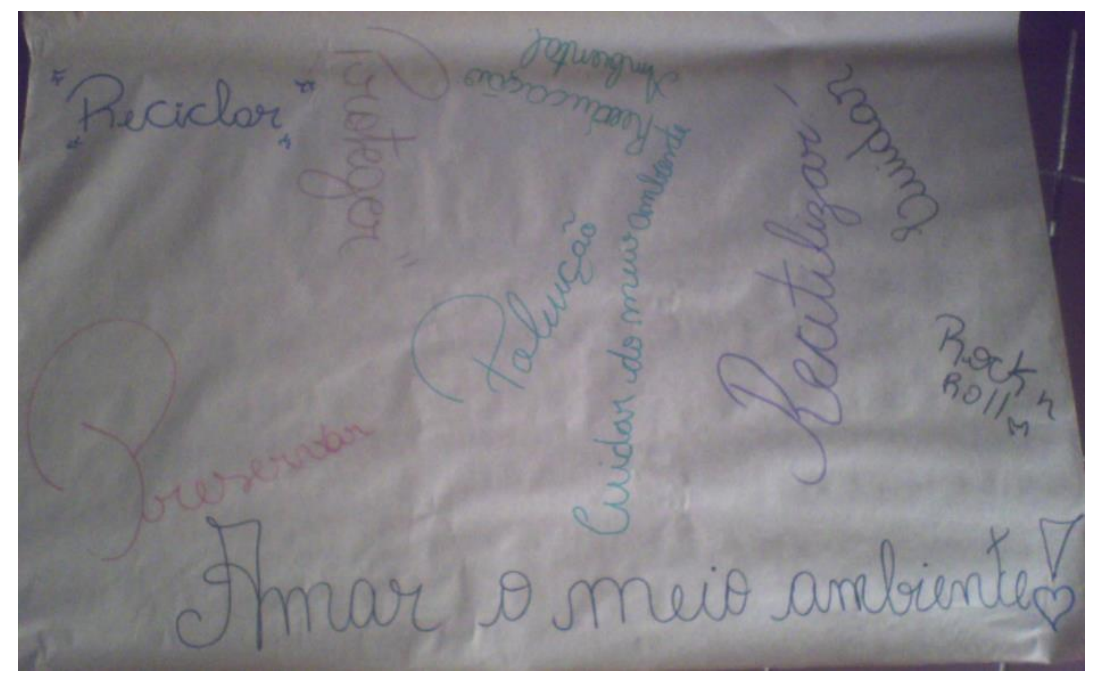

Figura 1- Significado de Educação Ambiental, caracterizado com um painel, no $1^{\circ}$ ano. Fonte: Autora

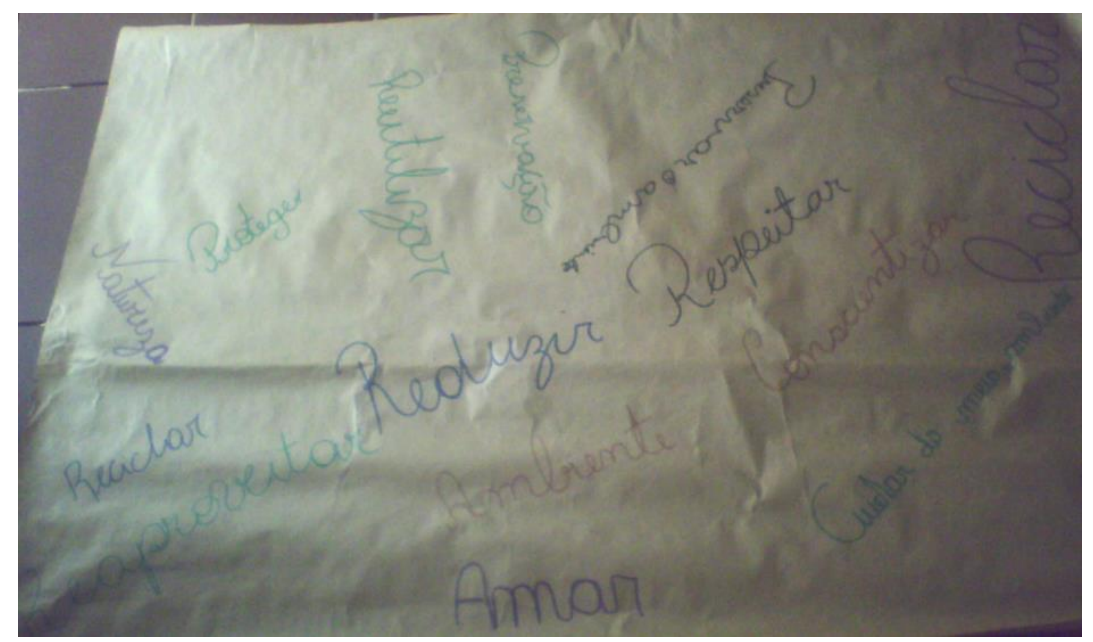

Figura 2- Significado de Educação Ambiental, identificado com um painel no 2⿳o ano.

Fonte: Autora

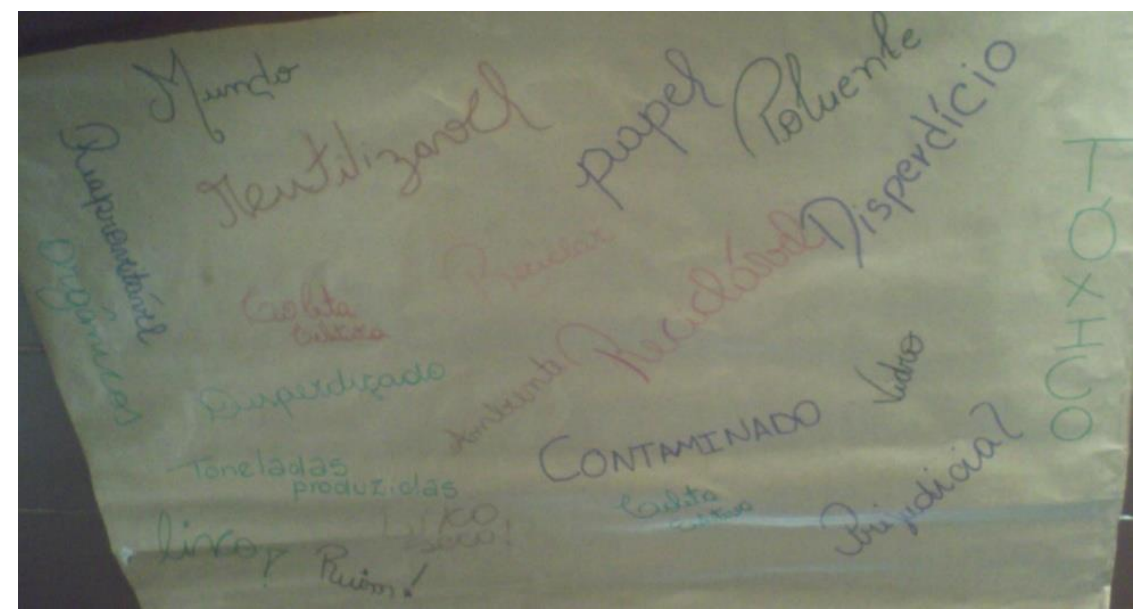

Figura 3- Significado de Educação Ambiental registrado com um painel, no 3º ano. Fonte: Autora 
Entender-se como ser social e atuante meio em que se vive, onde as ações que ocorrem no momento atual podem interferir na vida de várias pessoas, conhecidas ou não, dentro da sociedade, o aluno torna-se mais consciente sendo este um grande desafio.

O lixo é discutido às vezes como um grande problema social. Isto é reflexo de uma sociedade que começa a apresentar um novo olhar sobre os problemas sociais da humanidade. Sendo o mesmo relacionado de várias maneiras, sob vários aspectos. Aí se torna saliente a vivência pessoal de cada indivíduo. A preocupação em orientar os alunos apresenta um diferencial, no $2^{\underline{0}}$ ano do curso em diante.

As sugestões discutidas com o grupo, como por exemplos, as oficinas, a construção de brinquedos com sucata, sugerem a possibilidade de trabalhar os temas em sala de aula. Quando o aluno começa a questionar-se sobre a realidade e as possíveis mudanças, há a possibilidade de começar a pensar nas ações relacionadas ao Meio Ambiente. Trabalhar com ações de Educação Ambiental torna-se um desafio constante, embora haja alguma resistência com o tema abordado.

As discussões que envolvem as ações relacionadas à Educação Ambiental, por vezes pode ser algo à parte, não necessariamente ensinado diretamente na sala de aula. Pode estar presente nas entrelinhas, onde a abordagem do tema torna-se com o decorrer do tempo algo compreensível e não segmentado. Trabalhar a Educação Ambiental na escola e na comunidade é uma ação possível desde que haja incentivo e criatividade por parte de todos os participantes envolvidos.

Os alunos compreenderam o sentido de procurar aprender sobre a Educação Ambiental, bem como de tornarem-se multiplicadores das ações. Durante a oficina, as discussões tornaram-se abrangentes e criativas, aparecendo as expressões de cada aluno em um painel relacionando as ações de Educação Ambiental.

\section{Conclusões}

A educação ambiental, segundo a lei $n^{\circ}$ 9.795/1999, é um componente permanente e importante da educação nacional, devendo por isto, estar presente em todos as modalidades e níveis do processo educativo formal e não-formal. Pode colaborar muito para renovar o processo educativo propriamente dito, trazendo uma avaliação crítica constante, promovendo a adequação dos conteúdos à realidade local e a inclusão dos educandos em ações concretas de transformação da mesma. Para abordar esses princípios e alcançar seus objetivos a Educação Ambiental (EA) precisa de uma vasta quantidade de métodos e principalmente do preparo dos educadores neste sentido.

A palavra "lixo" incomoda, no sentido de tirar a estabilidade adquirida, como muitos alunos comentavam, "é só levar para o caminhão do lixo" e surgiram discussões " e depois, o que acontece? ", "por isso existem em alguns lugares seca, nos outros, enchentes", "dá para vender os materiais recicláveis" e os mais variados assuntos sobre mudanças climáticas, cidadania, foram surgindo. A escola pode contribuir significativamente para a formação da consciência ambiental por meio da educação formal, através de palestras, vídeos, discussões, desta forma os educandos conseguem através da multiplicação de informações atingir uma parcela maior da população, tanto para as pessoas na convivência familiar, quanto nas comunidades onde irão atuar como professores.

\section{Agradecimentos}

Agradeço a professora Flávia, bem como à direção, coordenação e ao corpo docente do Ins. Est. Educação Menna Barreto, por terem propiciado aos seus alunos as ações apresentadas nesta pesquisa.

\section{Referências}

BRASIL, Política Nacional de Educação Ambiental. Lei 9795/99. Brasília, 1999.BRASIL. Conselho Nacional de Meio Ambiente - CONAMA. Resolução № 275. 2001. 
BRASIL. Parâmetros Curriculares Nacionais: introdução aos parâmetros curriculares nacionais. Secretaria de Educação Fundamental. Brasília, DF. MEC/SEF, 1997.

DIAS, Genebaldo Freire. Educação ambiental: princípios e práticas. 9oㅡ. Ed. São Paulo: Gaia, 2004. FAZENDA, Ivani (Org.). Práticas Interdisciplinares na Escola. 10ªed. São Paulo: Cortez, 2005.

FREIRE, Paulo. Pedagogia da autonomia: saberes necessários à prática educativa. 39. ed. São Paulo: Paz e Terra, 1996.

GODINHO, E. M. S. O. A Educação Ambiental como parceira no tratamento de resíduos sólidos. NUPEAT-IESA-UFG, v.3, n.1, Jan./Jun., 2013, p. 78-93, ISSN 2237-079X.

JACOBI,P. Educação Ambiental , Cidadania e Sustentabildade. Cadernos de Pesquisa, n. 118, março/ 2003 Cadernos de Pesquisa, n. 118, p. 189-205, março/ 2003. Encontrado em < http://www.scielo.br/pdf/cp/n118/16834.pdf>

LEFF, E. Epistemologia ambiental. São Paulo: Cortez, 2001.

MARENGO, J.A. - Mudanças climáticas, condições meteorológicas extremas e eventos climáticos no Brasil. Disponível em:<http://www.fbds.org.br/fbds/IMG/pdf/doc-504.pdf.> Acessado em 29 de agosto de 2015.

MUNIZ, Agnaldo da Costa. Projeto Apoema. Encontrado em <http:// www.apoema.com.br /geral.htm > Acessado em 25 de junho de 2015.

PEDRINI, A. de G. Educação Ambiental: reflexões e práticas contemporâneas. RJ: Vozes, 1997.

SILVA, T. C. L. da, ROZA-GOMES, M.F., OLIVEIRA A.D. de. Educação ambiental: um relato de atividades com embasamento científico. Unoesc \& Ciência - ACBS, Joaçaba, v. 1, n. 2, p. 125-134, jul. /dez. 2010. Encontrado em: <editora.unoesc.edu.br/index.php/acbs/article/download/583/pdf_84> Acesso em 16/08/15.

SIRANGELO, F. R. Relação entre a ocorrência de inundações e enxurradas e os índices morfométricos das sub-bacias hidrográficas da Região Hidrográfica do Guaíba, Rio Grande do Sul, Brasil. Dissertação de Mestrado. UFRGS. Encontrado em $:<$ http://www.ufrgs.br/srm/ ppgsr/ publicacoes/ dissert_fabiana_sirangelo.pdf $>$ Acessado em 29 de agosto de 2015. 